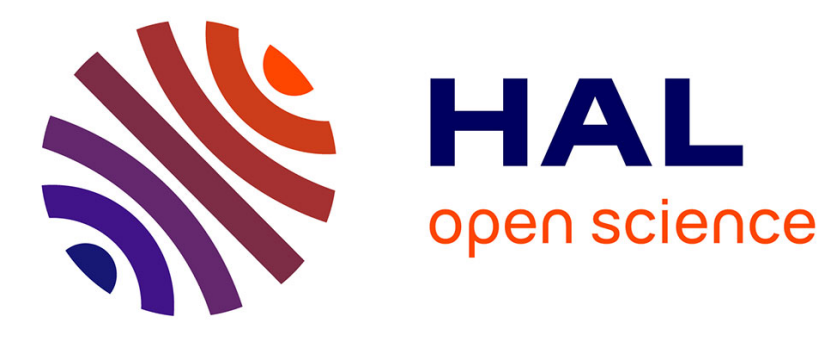

\title{
The Pathogenicity Island 2 regulator ssrA promotes reproductive tract but not intestinal colonization in chickens
}

Lotte Bohez, Inne Gantois, Richard Ducatelle, Frank Pasmans, Jeroen Dewulf, Freddy Haesebrouck, Filip van Immerseel

\section{To cite this version:}

Lotte Bohez, Inne Gantois, Richard Ducatelle, Frank Pasmans, Jeroen Dewulf, et al.. The Pathogenicity Island 2 regulator ssrA promotes reproductive tract but not intestinal colonization in chickens. Veterinary Microbiology, 2007, 126 (1-3), pp.216. 10.1016/j.vetmic.2007.06.025 . hal-00532289

\section{HAL Id: hal-00532289 \\ https://hal.science/hal-00532289}

Submitted on 4 Nov 2010

HAL is a multi-disciplinary open access archive for the deposit and dissemination of scientific research documents, whether they are published or not. The documents may come from teaching and research institutions in France or abroad, or from public or private research centers.
L'archive ouverte pluridisciplinaire HAL, est destinée au dépôt et à la diffusion de documents scientifiques de niveau recherche, publiés ou non, émanant des établissements d'enseignement et de recherche français ou étrangers, des laboratoires publics ou privés. 


\section{Accepted Manuscript}

Title: The Salmonella Pathogenicity Island 2 regulator ssrA promotes reproductive tract but not intestinal colonization in chickens

Authors: Lotte Bohez, Inne Gantois, Richard Ducatelle, Frank Pasmans, Jeroen Dewulf, Freddy Haesebrouck, Filip Van

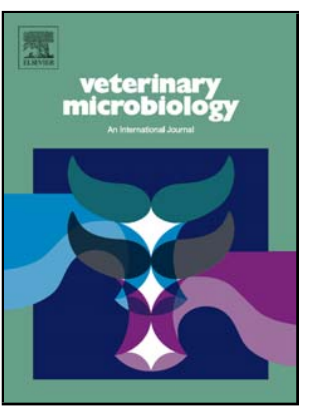

Immerseel

PII:

DOI:

S0378-1135(07)00325-2

Reference: doi:10.1016/j.vetmic.2007.06.025

VETMIC 3748

To appear in: $\quad$ VETMIC

Received date: $\quad 21-5-2007$

Revised date: 25-6-2007

Accepted date: $\quad$ 26-6-2007

Please cite this article as: Bohez, L., Gantois, I., Ducatelle, R., Pasmans, F., Dewulf, J., Haesebrouck, F., Van Immerseel, F., The Salmonella Pathogenicity Island 2 regulator ssrA promotes reproductive tract but not intestinal colonization in chickens, Veterinary Microbiology (2007), doi:10.1016/j.vetmic.2007.06.025

This is a PDF file of an unedited manuscript that has been accepted for publication. As a service to our customers we are providing this early version of the manuscript. The manuscript will undergo copyediting, typesetting, and review of the resulting proof before it is published in its final form. Please note that during the production process errors may be discovered which could affect the content, and all legal disclaimers that apply to the journal pertain. 
3 The Salmonella Pathogenicity Island 2 regulator ssrA promotes reproductive tract but not intestinal colonization in chickens

${ }^{1}$ Department of Pathology, Bacteriology and Avian Diseases, Research Group Veterinary Public

11 Health and Zoonoses, Faculty of Veterinary Medicine, Ghent University, Salisburylaan 133, B9820 Merelbeke, Belgium. 9820 Merelbeke, Belgium.

\footnotetext{
* Corresponding author. Mailing address : Department of Pathology, Bacteriology and Avian Diseases, Faculty of Veterinary Medicine, Ghent University, Salisburylaan 133, B-9820 Merelbeke, Belgium. Phone: (0032) 0926477 40. Fax: (0032) 0926477 89. E-mail: Lotte.Bohez@UGent.be
} 


\section{Abstract}

Using a deletion mutant in the regulator of SPI-2, ssrA, we investigated the role of SPI-2 in invasion, intestinal colonization and reproductive tract infection of chickens by Salmonella Enteritidis. The ssrA mutant was fully invasive in phagocytic and nonphagocytic cells but failed to persist within chicken macrophages. The ability of Salmonella Enteritidis to cause disease in orally infected 1 day-old chicks was not altered when $\operatorname{ssr} A$ was deleted. Furthermore, caecal colonization was not affected, while spleen and liver showed reduced colonization. Following intraperitoneal and intravenous infection of one day-old chicks, internal organ colonization was strongly reduced. After intravenous inoculation in adult laying hens bacterial numbers of the ssrA mutant were significantly lower in oviducts and ovaries as compared to the wild type strain. The chickens showed less reproductive tract lesions and the recovery of egg production was faster compared to the wild type strain infected chickens. These findings indicate that the SPI-2 regulator ssrA promotes reproductive tract colonization, but is not essential for intestinal colonization of chickens with the host non-specific serotype Enteritidis.

Keywords: Salmonella Enteritidis; Salmonella Pathogenicity Island 2 regulator ssrA; colonization; poultry

9

政




\section{Introduction}

Salmonella enterica serovar Enteritidis (Salmonella Enteritidis) is a facultative intracellular bacterium with a broad host range. It can cause foodborne illness in humans, following the consumption of chicken products (Guard-Petter, 2001). Poultry products become contaminated as asymptomatic carrier birds enter the slaughterhouse and asymptomatic carrier hens lay contaminated eggs. Infection of one day-old chickens with high doses of Salmonella Enteritidis can cause severe clinical salmonellosis with a high rate of mortality, while this serovar produces a chronic asymptomatic carrier state in low dosed infected young chickens and infected adult birds (Gast and Benson, 1995; Desmidt et al., 1997; Van Immerseel et al., 2004). These carrier birds may excrete the bacteria intermittently until slaughter age (6 weeks) in broilers until the end of the reproduction cycle in layer type chickens and thus constitute an important source of Salmonella infection (Gast and Benson, 1995; Desmidt et al., 1997; Humphrey et al., 1991). Salmonella Enteritidis specifically interacts with the reproductive organs of hens leading to egg contamination (De Buck et al., 2004). Following oral ingestion, Salmonella colonizes the chicken gut, especially the caeca, where it penetrates the mucosal epithelium (Desmidt et al., 1997). Interaction between Salmonella and the epithelium triggers infiltration of phagocytic cells to the infected site, where these cells take up the bacteria. Salmonella is capable to survive and replicate within bacterially modified macrophage spacious phagosomes, which can be attributed to the type III secretion system (TTSS) encoded by Salmonella pathogenicity island 2 (SPI-2) (Knodler and Steele-Mortimer, 2003). The infected phagocytes disseminate to the internal organs, such as liver, spleen and the reproductive tissues and thus spread the bacteria within the host (Turnbull and Snoeyenbos, 1974; Barrow et al., 1999). 
SPI-2 is an essential virulence locus for systemic disease in host-specific Salmonella serotypes including Salmonella Pullorum in poultry, and SPI-2 mutants fail to induce systemic disease and clinical signs in the infected animals (Jones et al., 2001; Wigley et al., 2002; Bispham et al., 2001).

The exact role of SPI-2 in the colonization and systemic spread of host non-specific serotypes and in the subsequent development of asymptomatic carriers in chickens however is currently not clear. Therefore, in this study, the role of ssrA in shedding, gut and internal organ colonization was investigated after oral inoculation of one day-old chickens with Salmonella Enteritidis. Organ colonization was evaluated after intraperitoneal inoculation of 5 day-old chickens and intravenous inoculation of adult laying hens to assess the role of ssrA in organ colonization, including oviduct and ovaria colonization and egg contamination, after passing the mucosal barrier of the gut.

\section{Materials and methods}

\subsection{Bacterial strain} strain was isolated from an outbreak of salmonellosis on a poultry farm. The nalidixic acid resistant strain and its $76 \mathrm{Sa} 88$ wild type progenitor strain are well-characterized (Bohez et al., 2006).

Salmonella Enteritidis phage type 4, strain $76 \mathrm{Sa} 88 \mathrm{Nal}^{\mathrm{r}}$ was used in the experiments. This 2006)

\subsection{Construction of defined mutant}


A deletion mutant in the Salmonella Pathogenicity Island 2 (SPI-2) encoded regulator SsrA was constructed according to the one-step inactivation method, first described by Datsenko and Wanner (2000). The targeted gene, ssrAI, was completely deleted from the start codon till the stop codon, as confirmed by sequencing.

\subsection{In vitro experiments}

\subsubsection{Invasion and survival in T84 and HD11 cell lines}

Invasion in T84 human colon carcinoma cell line was performed according to the setup of

Bohez et al. (2006.) Invasion and proliferation in HD11 chicken macrophage cells were determined by seeding the HD11-cells in a 24-well cell culture plates (Greiner, Frickenhausen, Germany) at a density of $5.10^{5}$ cells/well in culture medium. The bacteria were grown to stationary phase $(20 \mathrm{~h})$ at $37^{\circ} \mathrm{C}$ with shaking and added to the cells at a multiplicity of infection of $10(\mathrm{CFU} / \mathrm{cell})$. Inavsion and proliferation were determined after $1 \mathrm{~h}$ and $6 \mathrm{~h}$ of incubation, respectively. Experiments were performed in triplicate with 3 repeats in each experiment. Statistical analysis was performed by analysis of variance methods using SPSS 12.0 software.

\subsubsection{Cytotoxicity assay}

Cytotoxicity was assessed by measuring the lactate dehydrogenase (LDH) release (Cytotoxicity detection kit, Roche Diagnostic Corporation, Indianapolis, USA) of HD11 chicken macrophage cells. This assay is performed according to setup of Bohez et al. (2006). The bacteria were grown to stationary phase $(20 \mathrm{~h})$ at $37^{\circ} \mathrm{C}$ with shaking and added to the cells at a multiplicity of infection of 10 (CFU/cell). Cytotoxicity was determined after $6 \mathrm{~h}$ of incubation. 
116 The percentage of cytotoxicity was established using the following formula, instructed by the

117 Cytotoxicity detection kit (Roche):

119 Cytotoxicity $=($ experimental value - low control $) /($ positive control - low control $) \times 100$

\subsection{Experimental inoculation of chickens}

The experimental protocols were approved by the ethical committee of the Faculty of

Veterinary Medicine, Ghent University. Bacteria used for inoculation were grown for $20 \mathrm{~h}$ at $37^{\circ} \mathrm{C}$ in Luria-Bertani Broth (LB) on a shaker platform. The number of CFU/ml was determined were incubated aerobically for $20 \mathrm{~h}$ at $37^{\circ} \mathrm{C}$. The suspensions were kept at $4{ }^{\circ} \mathrm{C}$ until they were used in the assays. The bacterial cultures were diluted in phosphate buffered saline (PBS) to the respective inoculation density.

\subsubsection{Oral inoculation of one day-old SPF chicks}

Specific pathogen free (SPF) White Leghorn chickens (Charles River Laboratories, chicks were euthanized immediately after hatching and serum samples were taken for the detection of maternal antibodies against Salmonella Enteritidis by means of a previously described anti Salmonella Enteritidis ELISA, based on lipopolysaccharides of Salmonella 
group at the beginning of the experiment and cultured for Salmonella as described below. The chickens had ad libitum access to drinking water and feed. One day-old chicks were randomly divided in two groups of 61 and 62 chickens and orally inoculated in the crop using a plastic tube with $10^{8}$ colony forming units (CFU) of Salmonella Enteritidis $76 \mathrm{Sa} 88$ parent strain or its Salmonella Enteritidis $\Delta s s r A$ mutant in a volume of $0.2 \mathrm{ml}$ of PBS. At day 2, 4, 7, 10, 14, 21, 28, 36 and 42 post-hatch cloacal swabs were taken for the detection of Salmonella. For bacteriological analysis of caeca, liver and spleen, four chickens per group were euthanized at day $2,3,4,7,10,14,21$ and 28 post-hatch. On day 36 and day 42 of life 13 and 16 animals, and 6 and 9 chickens were euthanized in the groups infected with Salmonella Enteritidis 76Sa88 parent strain and its $\triangle s s r A$ mutant, respectively.

\subsubsection{Intra-peritoneal inoculation of five day-old SPF chicks}

An intra-peritoneal infection is very difficult in one day-old chickens because of the presence of the yolk sac. Therefore five day-old chickens were used in which the yolk sac was already reduced.

Specific pathogen free (SPF) White Leghorn eggs (Charles River Laboratories) were hatched and housed in isolation. Immediately after hatching, serum samples were taken from 10 chickens to detect maternal antibodies against Salmonella Enteritidis by means of an indirect ELISA (Desmidt et al., 1996). Before the start of the experiment cloacal swabs were taken from all chickens and cultured for Salmonella as described below. Feed and drinking water were provided ad libitum. Five day-old chicks were randomly divided in two groups of 24 chickens each and housed in separate HEPA-filtered rooms. The birds were intra-peritoneally inoculated 
162

163

164

165

166

167

168

169

170

171

172

173

174

175

176

177

178

179

180

181

182

183

with $10^{5}$ colony forming units (CFU) of Salmonella Enteritidis $76 \mathrm{Sa} 88$ parent strain or its isogenic $\Delta s s r A$ mutant in a volume of $0.2 \mathrm{ml}$ of PBS with $10 \mathrm{mg} / \mathrm{ml}$ methylene blue solution (UCB, Leuven, Belgium). Blue staining beneath the abdominal skin indicated a well performed intra-peritoneal infection. At 4, 24 and $48 \mathrm{~h}$ post-infection six chickens per group were euthanized and samples of caeca, liver and spleen were collected for the detection of Salmonella,

\subsubsection{Intravenous inoculation of adult SPF laying hens}

Fifteen SPF Lohmann white LSL hens (Lohmann Tierzucht GMBH, Cuxhaven, Germany) were housed in two separate HEPA-filtered rooms with both 10 animals. The birds received $16 \mathrm{~h}$ of light per day and had free access to food and water. At the age of 18 weeks, serum samples were taken from three hens of each group to test for anti-Salmonella Enteritidis antibodies in an LPS-ELISA (Desmidt et al.., 1996). On week 21, all the hens were in lay. At 24 weeks of age, all the animals were intravenously inoculated in the wing vein with $250 \mu 1$ containing $2 \times 10^{8} \mathrm{cfu}$ of the Salmonella Enteritidis $76 \mathrm{Sa} 88$ wild type strain or its $\Delta s s r A$ mutant strain. This protocol was already used to produce high levels of internal egg contamination (De Buck et al., 2004). Eggs were collected daily during 13 days. Two weeks after inoculation, all the animals were euthanized and liver, oviduct and ovary were aseptically removed for bacteriological analysis for Salmonella.

\subsubsection{Bacteriological analysis of cloacal swabs and organ samples}


Cloacal swabs were directly inoculated on BGA plates with $20 \mu \mathrm{g} / \mathrm{ml}$ nalidixic acid, which were incubated for $20 \mathrm{~h}$ at $37^{\circ} \mathrm{C}$. When negative after direct inoculation, samples were preenriched in buffered peptone water (BPW, Oxoid, Basingstoke, England) overnight at $37^{\circ} \mathrm{C}$, after which samples were enriched by addition of $1 \mathrm{ml}$ of this suspension to $9 \mathrm{ml}$ tetrathionate brilliant green broth. After incubation overnight at $37^{\circ} \mathrm{C}$, a loopful of this suspension was plated on BGA.

Samples of caeca, liver, spleen, oviduct and ovary were homogenised and 10-fold dilutions were made in buffered peptone water. For each dilution $6 \times 20 \mu l$ were inoculated on BGA plates with $20 \mu \mathrm{g} / \mathrm{ml}$ nalidixic acid. After incubation overnight $\left(37^{\circ} \mathrm{C}\right)$ the number of $\mathrm{CFU} / \mathrm{g}$ tissue was determined by counting the bacterial colonies. For samples which were negative after titration, pre-enrichment and enrichment was performed, as described above.

Samples that were negative after titration but positive after Salmonella enrichment were presumed to contain $10^{1} \mathrm{CFU} / \mathrm{g}$ organs. Samples that were negative after enrichment were presumed to have $0 \mathrm{CFU} / \mathrm{g}$. The mean $\mathrm{CFU} / \mathrm{g}$ tissue was calculated for each group.

\subsubsection{Bacteriological examination of eggs}

Upon collection, faeces on the surface of the eggs were removed and the eggs were decontaminated by dipping in ethanol (95\%) for $1 \mathrm{~min}$. The eggs were broken aseptically and homogenized. A volume of $40 \mathrm{ml}$ of BPW per egg was added and incubated $48 \mathrm{~h}$ at $37^{\circ} \mathrm{C}$. Enrichment was done in tetrathionate brilliant green broth at $37^{\circ} \mathrm{C}$ for $24 \mathrm{~h}$, where after a loopful of enrichment broth culture was streaked onto BGA plates supplemented with $20 \mu \mathrm{g} / \mathrm{ml}$ nalidixic acid. 


\subsubsection{Statistical analysis}

For each time point in the oral infection experiment, logistic regression (binary outcome variables) and general analysis of variance (continuous outcome variables) methods were used to determine significant differences between treated groups for the cloacal swab analysis and for analysis of the samples of caeca, liver and spleen, respectively.

In the intra-peritoneal and intravenous infection experiment, statistical analysis of organ colonisation was performed by general analysis of variance and the independent T-test., respectively. Statistical differences in egg production were determined by the chi-square analysis and differences in positive laid eggs by the Fisher's exact T-test. Differences with P-values below 0.05 were significant. All statistical analyses were performed using SPSS 12.0.

\section{Results}

3.1. Invasion in T84 human epithelial cells and uptake and proliferation in chicken macrophage HD11 cells

No statistically significant differences were observed in invasion of both Salmonella Enteritidis wild type strain and its $\Delta s s r A$ mutant strain in T84 cells and HD11 cells. The ssr $A$ mutant was significantly $(\mathrm{p}=0.006)$ reduced in its intramacrophage survival compared to the wild type strain. The relative intramacrophage survival percentage $(6 \mathrm{~h} / 1 \mathrm{~h})$ of the $\Delta s s t$ mutant was $62 \%$ of that of the wild type strain. 


\subsection{LDH assay}

The percentage of cytotoxicity at $6 \mathrm{~h}$ post-infection of HD11 cells with the Salmonella Enteritidis $s s r A$ mutant strain $(20 \% \pm 2.2)$ was similar to that of Salmonella Enteritidis $76 \mathrm{Sa} 88$ wild type strain $(21 \% \pm 2.4)$. No statistically significant differences could be observed. The results are calculated relative to triton-exposed cells $(100 \%)$.

\subsection{In vivo trials}

The pathogenic responses may vary between different serotypes, even strains, and different host infection models.

\subsubsection{Oral inoculation of one day-old SPF chicks}

No differences in clinical signs were observed between animals inoculated with either the parent strain or the $\Delta s s r A$ mutant. Both groups showed dullness, pasted vents and reduced appetite in the first days after inoculation. In the group inoculated with the Salmonella Enteritidis $\Delta s s$ mutant mortality was $27 \%$ compared with $15 \%$ in the group inoculated with Salmonella Enteritidis $76 \mathrm{Sa} 88$ wild type strain.

The chickens of both groups showed a similar faecal excretion pattern during the whole experiment (Table 1). Almost all cloacal samples were positive for Salmonella after enrichment in the 6 weeks of study. At direct plating in both groups a decrease in shedding was observed 
253

254

255

256

257

258

259

260

261

262 from day 21 of age and at the end of the experiment about $20 \%$ of the chickens yielded positive swabs in both groups.

The ability of Salmonella Enteritidis $76 \mathrm{Sa} 88$ wild type strain and its $\Delta s s r A$ mutant strain to colonize caeca, liver and spleen is presented in Fig.1. Analysis of the number of Salmonella $\left(\log _{10} \mathrm{CFU} / \mathrm{gr}\right.$ organ) recovered from the caeca showed no statistically significant differences between both groups. At 2 days post-infection a maximum level of colonization (ca. $10^{8} \mathrm{CFU} / \mathrm{g}$ ) was observed for both strains. Afterwards, the numbers of colonizing bacteria in the caeca gradually decreased over time. At 42 days the caecal samples of all animals remained positive after enrichment. One day after infection the counts of Salmonella Enteritidis 76Sa88 wild type strain and its $\operatorname{ss} A$ mutant strain were similar both in spleen (ca. $10^{2} \mathrm{cfu} / \mathrm{g}$ ) and liver (ca. $10^{3}$ $\mathrm{cfu} / \mathrm{g}$ ). The wild type strain peaked in liver and spleen at days 3 and 7 of age, respectively, reaching levels of about $\log 5.2$ and $\log 5.7$, while at these time points the $\operatorname{ssr} A$ mutant only reached levels of $\log 2.7$ and $\log 3.7$ for liver and spleen colonization. When comparing the numbers of wild type strain and the srrA mutant recovered from the spleen and liver over the full length of the experiment a significant $(\mathrm{p}<0.05)$ difference was found for both organs. At the end of the experiment $63 \%$ of the animals were positive for the wild type strain after enrichment, while only $22 \%$ of the birds were positive for the $\operatorname{ss} A$ mutant for both internal organs.

\subsubsection{Intra-peritoneal infection of five day-old SPF chicks}

The number of CFU per g liver and spleen of all inoculated animals at 4, 24 and $48 \mathrm{~h}$ after intra-peritoneal infection of five day-old chickens is presented in Fig.2. Similar levels of spleen and liver colonization were observed for the wild type strain and its $\operatorname{ssr} A$ mutant derivate at $4 \mathrm{~h}$ 
post-infection. In about $50 \%$ of the animals Salmonella could not be detected at direct plating. At $24 \mathrm{~h}$ post-infection, the $\operatorname{ssr} A$ mutant was statistically significantly reduced in liver and spleen colonization compared to its isogenic wild type strain. At direct plating, the $\operatorname{ssr} A$ mutant strain could not be isolated from any liver sample, whereas 5 of the 6 animals were positive for the wild type strain. Of the spleen samples, only 1 of 6 samples was positive at direct plating for the $\operatorname{ss} A$ mutant, while all samples were positive for the wild type strain. Compared to its isogenic wild type strain, the numbers of $\operatorname{ssr} A$ mutant bacteria colonizing liver and spleen was about 100 and 1000 fold, respectively, reduced (statistical significant with $\mathrm{p}<0.05$ ). At $48 \mathrm{~h}$ post-infection, no statistically significant differences could be detected anymore, although a decrease in liver and spleen colonization by the $\operatorname{ssr} A$ mutant strain was still present.

\subsubsection{Intravenous infection of adult SPF white LSL hens}

In the group inoculated with the wild type strain, 2, 1 and 1 chicken(s) died on day 2, 3 and 5 after infection, compared to death of one chicken on day 6 after inoculation in the $\operatorname{ssr} A$ mutant inoculated group. At time of organ collection, day 14 after infection, 6 and 9 chickens were left in the wild type and $\operatorname{ss} A$ mutant strain inoculated group, respectively.

Results of isolation of Salmonella Enteritidis wild type strain and Salmonella Enteritidis ssrA mutant strain from different organs at 2 weeks after intravenous infection of adult SPF laying hens are presented in Fig.3. Bacteriological analysis of the liver showed that the concentration of colonizing ssrA bacteria was significantly lower $(\mathrm{p}=0.02)$ in comparison to the wild type strain. At direct plating, $22 \%$ of the liver samples of chickens inoculated with the $s s r A$ mutant were negative, while all liver samples were positive at direct plating for the wild type strain bacteria. Intravenous inoculation with Salmonella Enteritidis wild type strain resulted in 
lesions of oviducts and ovaries. The oviducts were reduced in size and the ovaries were shrunked and had discolored follicles. These pathological changes in the reproductive tract were absent in the birds infected with the $\operatorname{ssr} A$ mutant. Animals infected with the $\operatorname{ssr} A$ mutant showed a significantly $(\mathrm{p}<0.01)$ lower colonization in ovary and oviduct in comparison to animals infected with the wild type strain, i.e. a decrease of about $\log 2.4$ and $\log 2.9$, respectively. In addition, the oviduct samples of only 4 of 9 chickens were positive for the $\operatorname{ssr} A$ mutant strain at direct plating, while all oviduct samples were positive in birds infected with the wild type strain. Egg production was reduced after infection with both Salmonella Enteritidis parent strain and its ssrA mutant derivate (Table 2). From day 7 to day 13 post-infection, laying hens in the ssr $A$ mutant inoculated group showed a significant higher egg production. At day 1 and 3 post-infection, 2 and $1 \mathrm{egg}(\mathrm{s})$ of a total number of 18 laid eggs, respectively, were found positive for Salmonella Enteritidis wild type strain (Table 2). The ssrA mutant strain could be isolated from the content of 1 egg of a total number of 33 laid eggs at day 3 post-infection.

\section{Discussion}

Various studies have, among others by means of an $\operatorname{ssr} A$ mutant, demonstrated that the function of the two-component regulatory system SsrA-B is crucial for the expression of all virulence genes within SPI-2 and various loci outside of SPI-2 encoding effector proteins of the SPI-2-TTSS (Cirillo et al., 1998; Lober et al., 2006).

The data presented here indicate that the SPI-2 regulator ssrA promotes reproductive tract infection of Salmonella Enteritidis in laying hens whereas it has no effect on intestinal colonization. The marked reduction in internal organ colonization observed after intraperitoneal and intravenous inoculation of the $\operatorname{ssr} A$ mutant confirms the role of the SPI-2 virulence genes in 
324

325

326

327

328

329

330

331

332

333

systemic spread and internal organ colonization. The reduced ssr $A$ colony counts in the oviducts and ovaries are indicative for the requirement of SPI-2 by Salmonella Enteritidis to spread to the reproductive tract tissues. This is reflected in the fact that less reproductive tract lesions were observed in the group of animals inoculated with the $\operatorname{ss} A$ mutant and the faster recovery of egg production after intravenous inoculation with the ssrA mutant. In vitro studies show that the ssrA mutant of Salmonella Enteritidis was as invasive as the parent strain in T84 intestinal epithelial cells but severely attenuated in intramacrophage survival in chicken macrophages. The ability of Salmonella Typhimurium to induce systemic infection in mice has been shown to be dependent on its survival within macrophages (Cirillo et al., 1998; Shea et al., 1999). Susceptible mice develop a severe systemic disease often resulting in death (Santos et al., 2001; Mastroeni et al., 2004), as is the case with other host-specific serotypes in other animal species (Pardon et al., 1988; Uzzau et al., 2000), including Salmonella Gallinarum biovar Pullorum in poultry (Pomeroy et al., 1991; Snoeyenbos et al., 1991). The Salmonella Pathogenicity Island 2 type three secretion system is an essential virulence locus for systemic disease in host-specific Salmonella serotypes (Jones et al., 2001; Wigley et al., 2002; Bispham et al., 2001). Whereas an ssrA mutant in the host non-specific serotype Enteritidis did not show colonization defects in one day-old chicks, the ssrA mutant in the host-specific serotype Gallinarum was found to be fully attenuated for its virulence in one day-old chicks following oral infection (Shah et al., 2005). In addition, a SPI-2 mutant of Salmonella Gallinarum carrying a mutation in the $s s a U$ gene was neither detected in the internal organs of orally infected 1 week-old chickens (biovar Pullorum, Wigley et al., 2002) nor in those of 3 week-old chickens (biovar Gallinarum, Jones et al., 2001). The involvement of SPI-2 in systemic colonization by host-specific serotypes in chickens was attributed to intramacrophage survival (Wigley et al., 2001). In this study, we have shown that in the host non- 
specific serotype Enteritidis, SPI-2 promotes the systemic spread to internal organs and reproductive tract tissue leading to persistent colonization of these organs.

The SPI-2 regulator ssrA is not an important factor for the enteric phase of the infection with this host non-specific serotype Enteritidis after oral inoculation of chickens: caecal colonization was not affected by the mutation, while spleen and liver colonization showed reduced colonization levels. Also Morgan et al. (2004) could not detect a role of SPI-2 in caecal colonization of chickens, although these authors only studied colonization early post-infection. Moreover, in rabbit ileal loops SPI-2 seems not required for the induction of enteropathogenic responses to serotype Typhimurium (Everest et al., 1999). SPI-2 is also not required for induction of enteritis in calves by Salmonella Typhimurium (Tsolis et al., 1999a). In contrast, Morgan et al. (2004) and Tsolis et al. (1999b) identified SPI-2 as an essential factor for efficient gut colonization of cattle.

In conclusion, the SPI-2 regulator ssrA plays an important role in reproductive tract colonization of Salmonella Enteritidis in laying hens. SsrA however does not play a major role in colonization of the chicken gut after oral infections with the host non-specific serotype Enteritidis. The SPI-2 knock-out mutant thus appears to be safe for laying hens, a characteristic which could hold promise for the future development of live vaccines. To provide complete elimination of prolonged shedding and subsequently egg contamination via egg shell penetration, extra attenuation of a live vaccine, for example by mutation of the gene candidate hilA (Bohez et al., 2006), is needed.

\section{Acknowledgements}


We would like to thank Sofie De Bruyckere for her skilful technical assistance. This work was funded by grant 2004 - 505523 of the European Union. Dr. Filip Van Immerseel is supported by a post-doctoral research grant of FWO Vlaanderen (Research Foundation - Flanders).

\section{References}

Barrow, P.A., 1999. Virulence of Salmonella enterica serovar Enteritidis. In : Saeed, A.M. (ed.). Salmonella enterica serovar Enteritidis in humans and animals, Iowa State University Press, Ames, USA, p. 173-181.

Bispham, J., Tripathi, B.N., Watson, P.R., Wallis, T.S., 2001. Salmonella pathogenicity island 2 influences both systemic salmonellosis and Salmonella-induced enteritis in calves. Infect. Immun. 69, 367-377.

Bohez, L., Ducatelle, R., Pasmans, F., Botteldoorn, N., Haesebrouck, F., Van Immerseel, F., 2006. Salmonella enterica serovar Enteritidis colonization of the chicken caecum requires the HilA regulatory protein. Vet Microbiol. 116, 202-210.

Cirillo, D.M., Valdivia, R.H., Monack, D.M., Falkow, S., 1998. Macrophage-dependent induction of the Salmonella pathogenicity island 2 type III secretion system and its role in intracellular survival. Mol Microbiol. 30, 175-188.

Datsenko, K.A., Wanner, B.L., 2000. One-step inactivation of chromosomal genes in Escherichia coli K-12 using PCR products. Proc. Natl. Acad. Sci. USA. 97, 6640-6645. 
De Buck, J., Van Immerseel, F. , Haesebrouck, F. , Ducatelle R., 2004. Colonization of the chicken reproductive tract and egg contamination by Salmonella. J. Appl. Microbiol. 97, 233245.

Desmidt, M., Ducatelle, R., Haesebrouck, F., De Groot, P.A., Verlinden, M., Wijffels, R., Hinton, M., Bale, J.A., Allen, V.M., 1996. Detection of antibodies to Salmonella Enteritidis in sera and yolks from experimentally and naturally infected chickens. Vet. Rec. 1338, 223-226.

Desmidt, M., Ducatelle, R., Haesebrouck, F., 1997. Pathogenesis of Salmonella Enteritidis phage type four after experimental infection of young chickens. Vet. Microbiol. 56, 99-109.

Everest, P., Ketley, J., Hardy, S., Douce, G., Khan, S., Shea, J., Holden, D., Maskell, D., Dougan. G., 1999. Evaluation of Salmonella typhimurium mutants in a model of experimental gastroenteritis. Infect. Immun. 67, 2815-2821. phage type 4 isolates and isolates of phage types commonly found in poultry in the United States.

412 Avian Dis. 39, 567-574.

414 Guard-Petter, J., 2001. The chicken, the egg and Salmonella Enteritidis. Environ. Microbiol. 3, $415 \quad 421-430$. 
417

418

419

420

421

422

423

424

425

426

427

428

429

430

431

432

433

434

435

436

437

438

439
Humphrey, T.J.,,Chart, H., Baskerville, A. and Rowe B. 1991. The influence of age on the response of SPF hens to infection with Salmonella Enteritidis PT4. Epidemiol Infect. 106, 33-43.

Jones, M.A., Wigley, P., Page, K..L. Hulme, S.D., Barrow, P.A., 2001. Salmonella enterica serovar Gallinarum requires the Salmonella pathogenicity island 2 type III secretion system but not the Salmonella pathogenicity island 1 type III secretion system for virulence in chickens. Infect. Immun. 69, 5471-5476.

Knodler, L.A., Steele-Mortimer, O., 2003. Taking Possession: Biogenesis of the SalmonellaContaining Vacuole. Traffic. 4, 587-599.

Löber, S., Jäckel, D., Kaiser, N., Hensel, M., 2006 Regulation of Salmonella pathogenicity island 2 genes by independent environmental signals. International Journal of Medical Microbiology $296,435-447$.

Mastroeni, P., Sheppard, M., 2004. Salmonella infections in the mouse model: host resistance factors and in vivo dynamics of bacterial spread and distribution in the tissues. Microbes Infect. $6,398-405$.

Morgan, E., Campbell, J.D., Rowe, S.C., Bispham, J., Stevens, M.P., Bowen, A., Barrow, P.A., Maskell, D.J., Wallis, T.S., 2004. Identification of host-specific colonization factors of Salmonella enterica serovar Typhimurium. Mol. Microbiol. 54, 994-1010. 
440

441

442

443

444

445

446

447

448

449

450

451

452

453

454

455

456

457

458

459

460

461

462

463
Pardon, P., Sanchis, R., Marly, J., Lantier, F., Pepin, M., Popoff, M., 1988. [Ovine salmonellosis caused by Salmonella abortus ovis] Ann Rech Vet. 19, 221-235. Review. French.

Pomeroy, B. S., Nagaraja, K. V, 1991. Fowl typhoid. In B. W. Calnek, H. J. Barnes, C. W. Beard, W. M. Reid, and H. W. Yoder (ed.), Diseases of poultry. Iowa State University Press, Ames. p. 87-99.

Santos, R.L., Zhang, S., Tsolis, R.M., Kingsley, R.A., Adams, L.G., Baumler, A.J., 2001. Animal models of Salmonella infections: enteritis versus typhoid fever. Microbes Infect. 3, 1335-44.

Shah, D.H., Lee, M.J., Park, J.H., Lee, J.H., Eo, S.K., Kwon, J.T., Chae, J.S., 2005. Identification of Salmonella gallinarum virulence genes in a chicken infection model using PCR-based signature-tagged mutagenesis. Microbiology. 151, 3957-3968.

Shea, J.E., Beuzon, C.R., Gleeson, C., Mundy, R., Holden, D.W., 1999. Influence of the Salmonella typhimurium pathogenicity island 2 type III secretion system on bacterial growth in the mouse. Infect. Immun. 67:213-219.

Snoeyenbos, G. H., 1991. Pullorum disease. In B. W. Calnek, H. J. Barnes, C. W. Beard, W. M. Reid, and H. W. Yoder (ed.), Diseases of poultry. Iowa State University Press, Ames. p. 73-86.

Tsolis, R.M., Adams, L.G., Ficht, T.A., Baumler, A.J., 1999a. Contribution of Salmonella typhimurium virulence factors to diarrheal disease in calves. Infect. Immun. 67, 4879-4885. 
464 465 466 467 468 469 470 471
Tsolis, R.M., Townsend, S.M., Miao, E.A., Miller, S.I., Ficht, T.A., Adams, L., Baumler, A.J., 1999b. Identification of a putative Salmonella enterica serotype typhimurium host range factor with homology to IpaH and YopM by signature-tagged mutagenesis. Infect. Immun. 67, 63856393.

Turnbull, P.C., Snoeyenbos, G.H., 1974. Experimental salmonellosis in the chicken. 1. Fate and host response in alimentary canal, liver, and spleen. Avian Dis. 18, 153-77.

Uzzau, S. , Brown, D.J., Wallis, T.S., Rubino, S., Leori, G., Bernard, S., Casadesus, J., Platt, D.J., Olsen, J.E., 2000. Host adapted serotypes of Salmonella enterica. Epidemiol. Infect. 125, 229255.

Van Immerseel, F., De Buck, J., Pasmans, F., Bohez, L., Boyen, F., Haesebrouck, F. and Ducatelle, R. 2004. Intermittent long-term shedding and induction of carrier birds after infection of chickens early posthatch with a low or high dose of Salmonella Enteritidis. Poult Sci. 83, $1911-1916$.

Wigley, P., Berchieri, A., Jr, Page, K.L., Smith, A.L., Barrow, P.A., 2001. Salmonella enterica serovar Pullorum persists in splenic macrophages and in the reproductive tract during persistent, disease-free carriage in chickens. Infect. Immun. 69, 7873-7879.

Wigley, P., Jones, M.A., Barrow, P.A., 2002. Salmonella enterica serovar Pullorum requires the Salmonella pathogenicity island 2 type III secretion system for virulence and carriage in the chicken. Avian Pathol. 31, 501-506. 
Figure 1. $\log _{10} \mathrm{CFU}$ of Salmonella Enteritidis $76 \mathrm{Sa} 88$ wild type strain (•) and Salmonella Enteritidis $\Delta s s r A$ mutant ( $\boldsymbol{\square})$ in the caeca (black lines), liver (grey lines) and spleen (light grey lines) of chicks dosed orally at one day-old and then euthanized at day $2,3,4,7,10,14,21$, 28, 36 and 42 of age. Each time point represents four chicks, with the exception of day 36 and day 42. In the groups infected with Salmonella Enteritidis $76 \mathrm{Sa} 88$ wild type strain 13 and 16 animals were euthanized on day 36 and day 42, respectively. In the groups infected with Salmonella Enteritidis $\Delta s s r A$ mutant 6 and 9 chickens were euthanized on day 36 and day 42 , respectively. The error bars present the standard error of the means (SEM).

Figure 2. $\log _{10} \mathrm{CFU}$ of Salmonella Enteritidis $76 \mathrm{Sa} 88$ wild type strain $(\bullet)$ and Salmonella Enteritidis $\Delta s s r A$ mutant ( $\mathbf{\square})$ in the liver (black dots) and spleen (grey dots) of chicks infected intra-peritoneally at five days-old. At 4, 24 and 48 hrs post-infection six chickens per group were euthanized. Each dot represents one chick, if more; the number of birds is indicated by $\mathrm{n}=$.

Figure 3. Liver and reproductive tract colonization by Salmonella Enteritidis $76 \mathrm{Sa} 88$ wild type strain (black bars) and Salmonella Enteritidis 76Sa88 ssrA mutant strain (grey bars) 14 days after intravenous infection of adult SPF laying hens. 


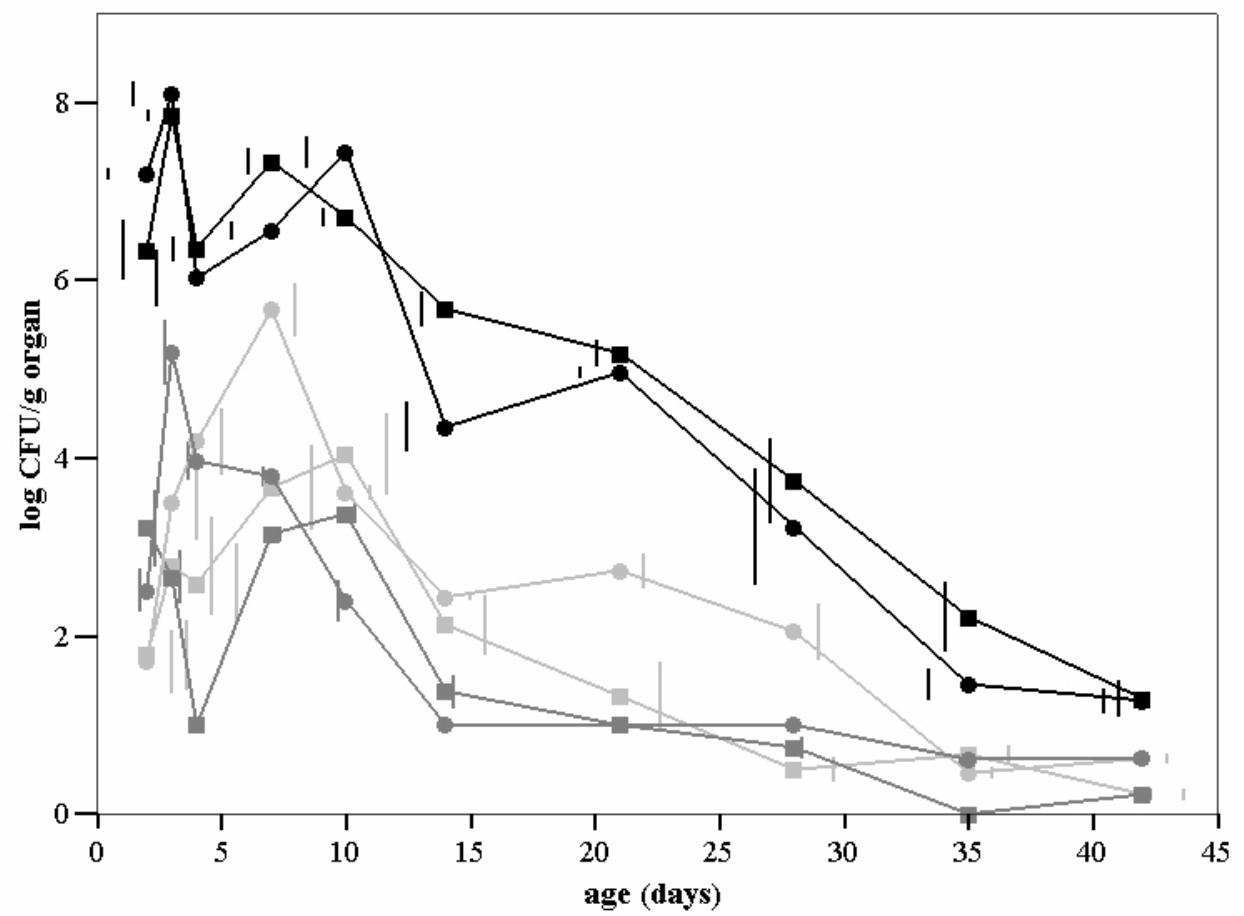

Figure 1 


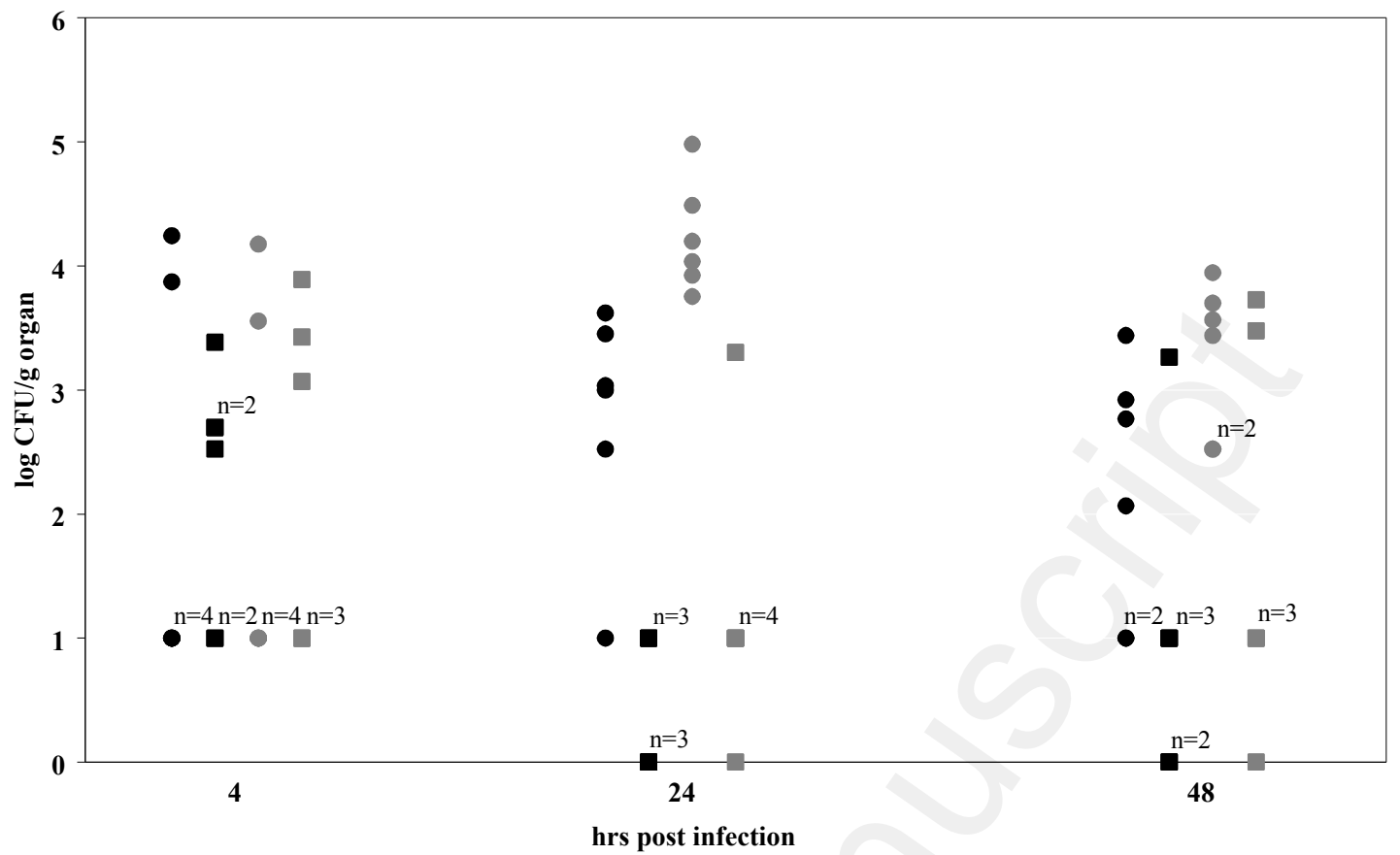

Figure 2 


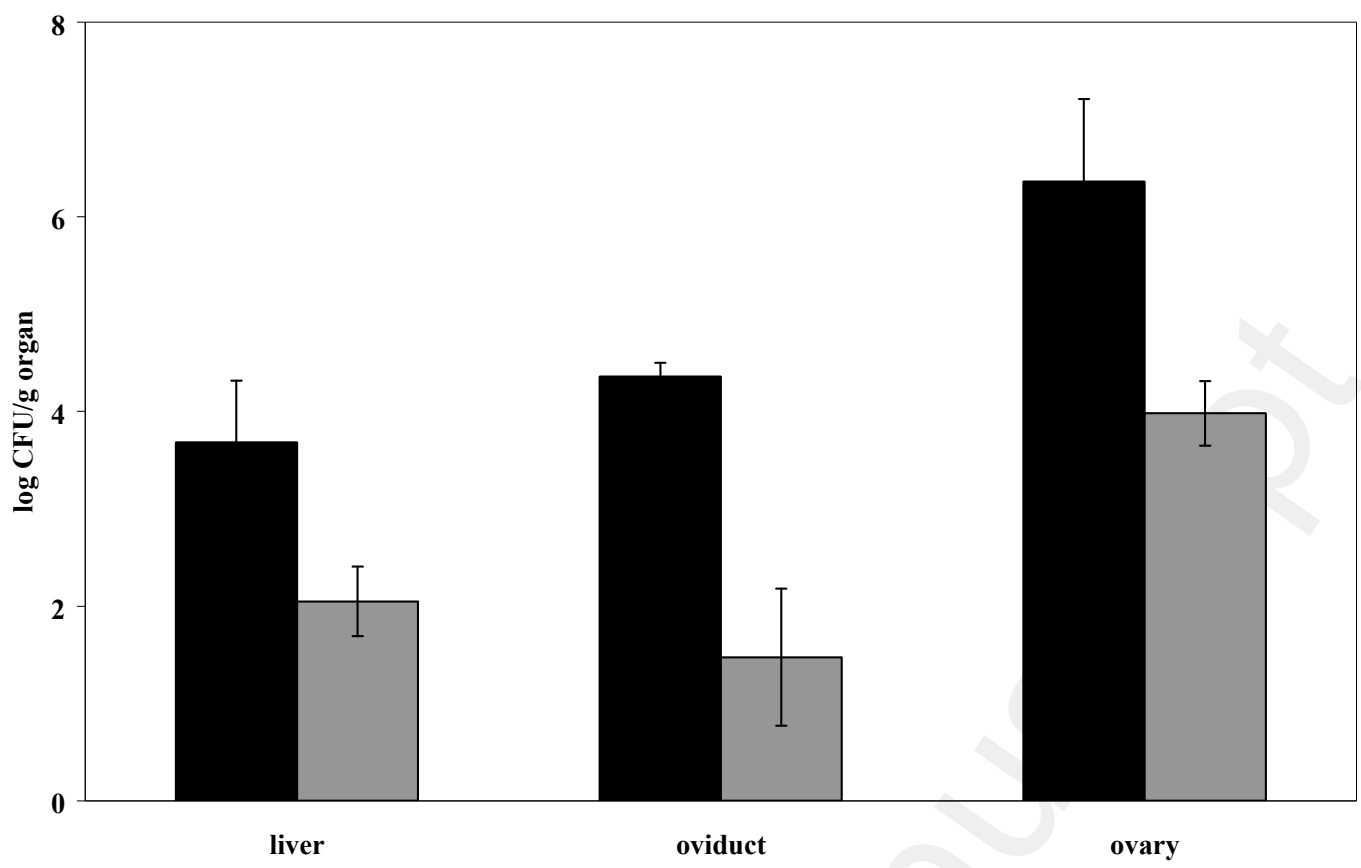

Figure 3 
Table 1. Numbers of chickens positive at cloacal sampling after oral inoculation at day of hatch with $10^{8}$ cfu Salmonella Enteritidis $76 \mathrm{Sa} 88$ wild type strain (WT) or its $\Delta s s r A$ mutant strain (SsrA). Samples were taken at 2, 4, 7, 10, 14, 21, 28, 36 and 42 days of age.

${ }^{a}$ Numbers of positive samples after enrichment / total number of samples.

${ }^{\mathrm{b}}$ Number of positive samples after direct plating.

Table 2. Egg production and number of Salmonella positive eggs 1 to 13 days following intra-venous infection of adult SPF laying hens with Salmonella Enteritidis 76Sa88 wild type strain (WT) or its $\Delta s s r A$ mutant strain (SsrA).

${ }^{a}$ Numbers of eggs laid/ total number of laying hens.

${ }^{\mathrm{b}}$ Number of positive egg contents. 
Table 1

days of age

\begin{tabular}{|c|c|c|c|c|c|c|c|c|c|}
\hline & 2 & 4 & 7 & 10 & 14 & 21 & 28 & 36 & 42 \\
\hline WT & $61^{\mathrm{a}} / 61\left(61^{\mathrm{b}}\right)$ & $53 / 53(52)$ & 49/49(48) & $45 / 45(45)$ & $41 / 41(40)$ & $37 / 37(22)$ & $28 / 33(14)$ & $25 / 29(10)$ & $14 / 16(3)$ \\
\hline SsrA & $62 / 62(62)$ & 49/49(48) & $41 / 41(38)$ & $35 / 35(34)$ & $27 / 27(25)$ & $23 / 23(13)$ & $12 / 19(7)$ & $11 / 15(8)$ & $4 / 9(2)$ \\
\hline
\end{tabular}


Table 2

days post-infection

\begin{tabular}{cccccccccccccc} 
& 1 & 2 & 3 & 4 & 5 & 6 & 7 & 8 & 9 & 10 & 11 & 12 & 13 \\
\hline WT & $5^{\mathrm{a}} / 6\left(2^{\mathrm{b}}\right)$ & $1 / 6(0)$ & $2 / 6(1)$ & $1 / 6(0)$ & $1 / 6(0)$ & $1 / 6(0)$ & $1 / 6(0)$ & $2 / 6(0)$ & $1 / 6(0)$ & $1 / 6(0)$ & $0 / 6(0)$ & $1 / 6(0)$ & $1 / 6(0)$ \\
SsrA & $2 / 9(0)$ & $1 / 9(0)$ & $2 / 9(1)$ & $1 / 9(0)$ & $1 / 9(0)$ & $2 / 9(0)$ & $6 / 9(0)$ & $2 / 9(0)$ & $2 / 9(0)$ & $5 / 9(0)$ & $2 / 9(0)$ & $2 / 9(0)$ & $5 / 9(0)$ \\
\hline
\end{tabular}

